OPEN ACCESS

Edited by:

Donald Sodora,

Seattle Children's Research Institute,

United States

Reviewed by:

Anne B. Krug,

Ludwig Maximilian University of

Munich, Germany

Johan Van Weyenbergh,

KU Leuven, Belgium

*Correspondence:

Rafaela Pires da Silva

rafaela.s@edu.pucrs.br

Ana Paula Duarte de Souza

ana.duarte@pucrs.br

Specialty section: This article was submitted to

Viral Immunology,

a section of the journal

Frontiers in Immunology

Received: 22 January 2021 Accepted: 26 April 2021

Published: 12 May 2021

Citation:

da Silva RP, Gonçalves JIB, Zanin RF, Schuch FB and de Souza APD (2021)

Circulating Type I Interferon Levels and

COVID-19 Severity: A Systematic

Review and Meta-Analysis.

Front. Immunol. 12:657363.

doi: 10.3389/fimmu.2021.657363

\section{Circulating Type I Interferon Levels and COVID-19 Severity: A Systematic Review and Meta-Analysis}

\author{
Rafaela Pires da Silva ${ }^{1 *}$, João Ismael Budelon Gonçalves ${ }^{2}$, Rafael Fernandes Zanin ${ }^{3}$, \\ Felipe Barreto Schuch ${ }^{4}$ and Ana Paula Duarte de Souza ${ }^{2 *}$

\begin{abstract}
${ }^{1}$ Biomedical Graduate Course, School of Health and Life Science, Pontifical Catholic University of Rio Grande do Sul, Porto Alegre, Brazil, 2 Laboratory of Clinical and Experimental Immunology, School of Health and Life Science, Pontifical Catholic University of Rio Grande do Sul, Porto Alegre, Brazil, ${ }^{3}$ Department of Health and Human Development, La Salle University, Canoas, Brazil, ${ }^{4}$ Department of Sports Methods and Techniques, Federal University of Santa Maria, Santa Maria, Brazil
\end{abstract}

Introduction: Coronavirus disease 2019 (COVID-19) is caused by severe acute respiratory syndrome coronavirus 2 (SARS-CoV-2) infections, resulting in a range of clinical manifestations and outcomes. Laboratory and immunological alterations have been considered as potential markers of disease severity and clinical evolution. Type I interferons (IFN-I), mainly represented by IFN- $\alpha$ and $\beta$, are a group of cytokines with an important function in antiviral responses and have played a complex role in COVID-19. Some studies have demonstrated that IFN-I levels and interferon response is elevated in mild cases, while other studies have noted this in severe cases. The involvement of IFN-I on the pathogenesis and outcomes of SARS-CoV-2 infection remains unclear. In this study, we summarize the available evidence of the association of plasma protein levels of type I IFN with the severity of COVID-19.

Methods: The PRISMA checklist guided the reporting of the data. A systematic search of the MEDLINE (PubMed), EMBASE, and Web of Science databases was performed up to March of 2021, looking for articles that evaluated plasma protein levels of IFN-I in mild, severe, or critical COVID-19 patients. Comparative meta-analyses with random effects were performed to compare the standardized mean differences in plasma protein levels of IFN-I of mild versus severe and mild versus critical patients. Meta-regressions were performed to test the moderating role of age, sex, time that the IFN-I was measured, and limit of detection of the assay used in the difference between the means.

Results: There was no significant difference in plasma levels of IFN- $\alpha$ when comparing between mild and severe patients $(\mathrm{SMD}=-0.236,95 \% \mathrm{Cl}-0.645$ to $0.173, \mathrm{p}=0.258, \mathrm{I} 2=$ 82.11), nor when comparing between patients mild and critical $(S M D=0.203,95 \% \mathrm{Cl}$ -0.363 to $0.770, p=0.481,12=64.06)$. However, there was a significant difference between healthy individuals and patients with mild disease (SMD $=0.447,95 \% \mathrm{Cl} 0.085$ to $0.810, p=0.016,12=62.89$ ).

Conclusions: Peripheral IFN- $\alpha$ cannot be used as a severity marker as it does not determine the clinical status presented by COVID-19 patients.

Keywords: COVID-19, severity, biomarker, type I interferon, IFN- $\alpha$ 


\section{INTRODUCTION}

Coronavirus disease 2019 (COVID-19) is caused by severe acute respiratory syndrome coronavirus 2 (SARS-CoV-2) infections, which has already affected more than $134,525,543$ people in 217 countries and territories (1). COVID-19 has been considered a pandemic since March 11, 2020, causing more than 2 million deaths globally. SARS-CoV-2 can be transmitted from person to person through droplets from breathing, coughing, sneezing, talking, or through direct contact with contaminated individuals or objects and surfaces (2). The average incubation period is 5 days (3), and the most prevalent signs and symptoms are fever, cough, headache, myalgia, fatigue, gastrointestinal symptoms, and dyspnea (4,5). COVID-19 causes distinct clinical manifestations among affected individuals, ranging from asymptomatic cases to cases with mild, moderate, severe, or critical symptoms, where they might progress to an acute respiratory distress syndrome (SARS) or even to dysfunction of multiple organs, complications that lead to death $(6,7)$. The risk of developing a more aggressive disease condition is influenced by age and the presence of comorbidities, such as diabetes, hypertension, obesity, and cardiovascular diseases $(2,8)$. Markers, such as the increase in C-reactive protein (CRP), Ddimer, and prothrombin time, are important to predict the outcome of the disease $(9,10)$. Also, immunological disorders were observed, such as leukopenia $(11,12)$, as well as a significant increase in serum cytokines levels, such as IL-6, TNF- $\alpha$, and IL- 8 $(12,13)$. Among the altered cytokines, interferons present conflicting results (14).

Interferons are divided into type I (IFN- $\alpha$ and IFN- $\beta$ ), type II (IFN- $\gamma$ ), and type III (IFN- $\lambda$ ) and have a fundamental role in the innate immune system, being part of the first line of defense against viral infections (15). In humans, the type I IFN (IFN-I) family consists of multi-genes that encodes 13 partially homologous IFN- $\alpha$ subtypes (IFN- $\alpha 1, \alpha 2, \alpha 4, \alpha 5, \alpha 6, \alpha 7, \alpha 8$, $\alpha 10, \alpha 13, \alpha 14, \alpha 16, \alpha 17$, and $\alpha 21)$ and genes that encodes IFN$\beta$, IFN- $\varepsilon$, IFN- $\kappa$, and IFN- $\omega(16,17)$. Among the IFN- $\alpha 2$ present subvariants, the best described are $\alpha 2 \mathrm{a}$ and $\alpha 2 \mathrm{~b}$ (18). Type I interferons (IFN-I) act as inhibitors of viral replication in infected cells and have a defensive action in uninfected cells. IFN-I can affect dendritic cells, B, T, and NK cells function, enhancing immune response. Most infected cell types can produce IFN- $\beta$, but IFN- $\alpha$ is mainly produced by hematopoietic cells $(19,20)$. Plasmacytoid dendritic cells (pDCs) are considered as a major producer of IFN- $\alpha$ (21). These cells detect viruses through TLR7 and TLR9, inducing secretion of IFN-I through the MyD88-IRF7 signaling pathway $(22,23)$.

IFN-I is produced rapidly after virus infection and exhibits antiviral activity by binding to its receptor IFNAR and inducing the expression of the interferon-stimulated genes (ISGs) (24). ISGs play an important role in viral infection, presenting an inhibitory effect at different stages of viral replication, such as viral membrane fusion and viral gene expression. They are responsible for the direct antiviral effects or molecules that can regulate IFN-I induction and signal (24-27). Some ISGs can control cell death and metabolism, RNA degradation, and protein synthesis. The IFN-I response can recruit several immune cells and lead to inflammatory disease, and this can develop beneficial or detrimental outcomes for the host (17). Despite its great importance in the antiviral response, the role of IFN-I in COVID-19 is complex (28-30); some studies have suggested a protective role for IFN-I during infection $(31,32)$, while other studies suggested a deleterious role for IFN-I in COVID-19 (33, 34).

Aging impairs the IFN-I production in pDCs $(35,36)$. Monocytes from the elderly exhibited impaired RIG-I signaling due to the absence of TRAF3, reducing induction of IFN-I production (37). Also, pDC from healthy males produces less IFN-I after stimulation comparing to females (38). These findings might explain why the elderly are more susceptible to complications from the SARS-CoV-2 infection $(39,40)$ and the higher prevalence of COVID-19 in men (41). In contrast, smoking and body mass index (BMI) also affect the expression of IFN-I but increasing it, and these two factors tend to worsen the clinical course of the SARS-CoV-2 infection (42). Also, the response to IFN-I was initially considered an inducer of the virus receptor, the angiotensin-converting enzyme 2 (ACE2) (43), which could worsen the patient's condition. However, it has recently been shown that interferon induces an ACE2 isoform, which does not function as a virus receptor (44).

IFN-I is used to treat various diseases, including hepatitis $\mathrm{C}$ $(45,46)$ and B (47), multiple myeloma (48), polycythemia Vera (49), and are also tested for the treatment of COVID-19. Studies carried out with inhaled or intramuscularly administered IFN$\alpha 2 b$ have demonstrated that treatment can accelerate viral clearance and reduce circulating IL-6 and CRP levels (50), in addition to preventing disease progression (51). IFN- $\beta$ - $1 \mathrm{~b}$ used subcutaneously effectively decreased the time to clinical improvement in severe COVID-19 patients (52). However, IFN- $\beta$ used subcutaneously did not reduce mortality in patients with COVID-19 in a large clinical study conducted by WHO in 30 countries (53). Conversely, inhaled IFN- $\beta 1$ a improved the recovery time for patients infected with SARSCoV-2 (54). In a descriptive review of literature about the role of IFN-I in treating COVID-19, it is highlighted that IFN- $\alpha$ use at the early phase of COVID-19 presents a positive outcome, but IFN- $\beta-1 \mathrm{a}$ and $-1 \mathrm{~b}$ are more effective to hinder COVID-19 (55). A systematic review and meta-analysis have been previously performed to evaluate the effects of IFN-I and Janus Kinaseinhibitors as treatments for COVID-19 patients and their effectiveness to produce positive outcomes (56). They found that IFN-I treatment is associated with positive clinical outcomes regarding mortality and discharge (56). The time to start IFN-I treatment might be crucial (57).

Disagreements related to the role of IFN-I in patients with COVID-19 demonstrate the importance of further studying these cytokines in the disease. The importance of IFN-I in the pathogenesis of the COVID-19 had been previously reviewed (30,57-61). Nonetheless, the available evidence regarding the circulating levels of IFN-I and its response and the association with the severity of the disease has not been meta-analyzed. 
This review aims to integrate the different studies on this subject to verify whether the increase or decrease levels of IFN-I in serum/plasma from patients with COVID-19 is linked to the disease severity.

\section{METHODOLOGY}

\section{Search Strategy}

The articles search was carried out by two reviewers (RPS and JIBG), from August 25 to March 21, 2021, in three different bibliographic databases - MEDLINE (PubMed), EMBASE, and Web of Science. The terms used were ("COVID-19" OR "SARSCOV-2" OR “Coronavirus Infections") AND ("IFN" OR "Interferon type I" OR "Interferon-alpha" OR "Interferonbeta"). Additional research was also carried out on the references of the articles that had the full reading in the second screening phase, and searching in the Research Gate and medRxiv, using the same terms listed above, looking for studies not yet peer-reviewed.

\section{Inclusion and Exclusion Criteria}

All articles that performed comparisons between plasma protein levels of IFN-I ( $\beta, \alpha$, and subtypes) in patients with different degrees of COVID-19 severity (mild, severe, and critical) were included. Studies that did not present the mean and standard deviation values or errors in the text or figures were excluded. Review articles and meta-analyses were excluded.

\section{Data Extraction}

Authors, publication date, study design, number of participants included (healthy, mild, severe, and critical), mean age, gender, symptoms related to COVID-19, criteria used for classification severity of the disease, comorbidities, IFN-I levels in plasma/ serum, methodology for IFN-I analysis, and days after infection that IFN-I was measured were extracted from each of the selected articles. The data of IFN- I levels presented in the format of a graph were extracted using the Graph Grabber software (62).

\section{Quality Assessment}

The methodological quality of the studies was evaluated with the Newcastle-Ottawa scale (63). The quality score of the casecontrol studies was calculated according to three aspects: the selection of cases and controls (0-4 stars); the comparability of cases and controls (0-2 stars); and the outcomes evaluation (0-3 stars). The maximum score is nine stars, representing high methodological quality.

\section{Statistical Analysis}

Comparative meta-analyses of plasma protein levels of IFN- $\alpha$ were performed between patients with mild versus severe and mild versus critical COVID-19 and between healthy individuals versus patients with mild COVID-19 and healthy individuals versus patients with severe COVID-19. Due to clinical heterogeneity, the use of meta-analyses of random effects was established a priori. The effects of individual studies were calculated using the standardized mean difference (SMD) and 95\% confidence interval $(95 \% \mathrm{CI})$. Effect sizes are considered weak if $>0.2$, moderate if $>0.5$, or strong if $>0.8$ (64). The heterogeneity of effects between studies was calculated using the $\mathrm{I}^{2}$ test (65). Meta-regressions were performed to explore whether age, sex, time that the IFN-I was measured, and limit of detection of the assay used are moderators of the difference between different groups. Subgroup analyzes were performed to verify how much the different measuring techniques used influence heterogeneity. Finally, the Egger (66) and Begg-Mazumbar (67) regression tests were performed, together with the visual analysis of the Funnel plot, to assess the presence of publication bias.

\section{RESULTS}

\section{Search Results}

The searches of the databases resulted in 1564 articles. Another 17 articles were added manually through searches on Research Gate and medRxiv as they have potentially relevant titles and abstracts. After removing 699 duplicates, 819 articles were excluded for their titles and abstracts. Afterward, 63 studies were read entirely. Of these, 15 studies were included in the meta-analysis (68-81). Figure 1 represents the flowchart of the meta-analysis containing the details of the articles excluded in each of the stages, including the reason for their exclusions. A complete table listing those articles excluded after an evaluation is given Supplementary Material $\mathbf{1}$.

\section{Description of Studies and Participants}

The measurement of IFN- $\alpha$ was presented in all studies, while of IFN- $\beta$ in only two of them. The methods used for measuring IFN- $\alpha$ were ELISA, single molecular array (Simoa), Luminex magnetic bead, electrochemiluminescent, bead-based immunoassay for flow cytometry, and microfluid immunoassay fluorescence detection. The average age of participants was 43 to 63 years, and the percentage of male participants ranged from 42 to $83 \%$. The comparison between mild and critical was performed in four of the studies, between mild and severe in 15 studies and between healthy and mild and healthy and severe in nine studies. The cases were considered mild to moderate when presenting fever, myalgia, fatigue, diarrhea, signs of pneumonia on chest CT scan, and requirement of up to $3 \mathrm{~L} / \mathrm{min}$ of supplemental oxygen to maintain more than $92 \%$ SpO2 (6876). Severe cases were characterized by the need for admission to the intensive care unit (ICU) due to breathing difficulties, needing more than $3 \mathrm{~L} / \mathrm{min}$ of oxygen, and partial pressure of arterial oxygen $(\mathrm{PaO} 2) /$ fraction of inspired oxygen $(\mathrm{FiO} 2) \leq 300 \mathrm{mmHg}$ (69-74, 76, 77). Critically ill patients had respiratory failure, septic shock, and/or multiple organ dysfunction or failure (70$75,77)$. Table 1 contains the main characteristics of the selected studies.

\section{Quality Assessment}

The general methodological quality of the studies included in this review was high, with all the studies presenting scores on the 


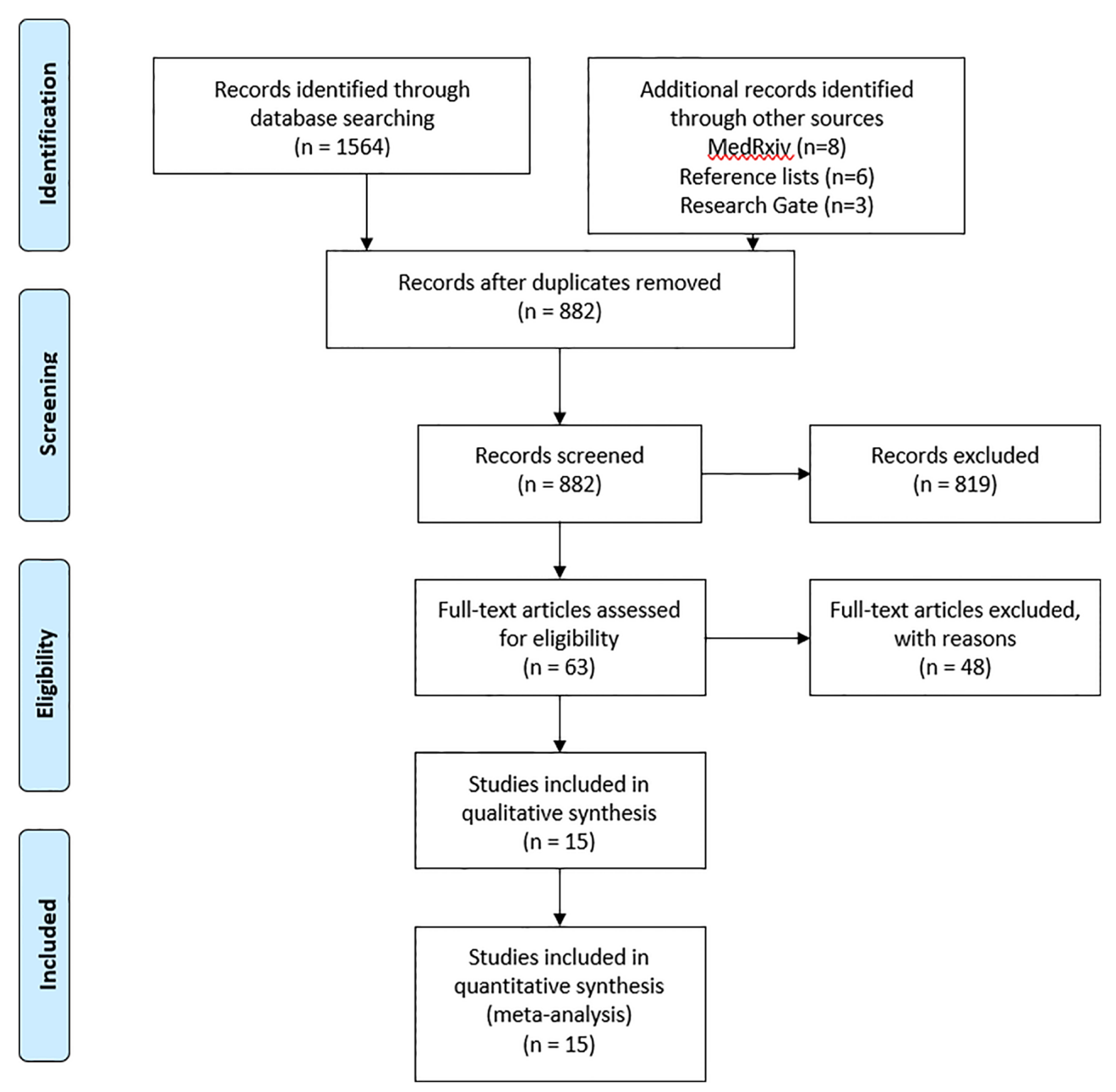

FIGURE 1 | Flowchart of article selection.

Newcastle-Ottawa scale ranging from 7 to 8, demonstrating good methodological quality (Table 2).

\section{Meta-Analysis}

The pooled data from 15 studies showed a non-significant difference between patients with mild and severe disease $(\mathrm{SMD}=-0.236,95 \% \mathrm{CI}-0.645$ to $0.173, \mathrm{p}=0.258, \mathrm{I} 2=82.11)$ (Figure 2). A subgroup analysis was made exploring how much the analysis technique explains heterogeneity. When the single molecular array (Simoa) was used there was a significant difference in the analysis $(\mathrm{p}=0.001)$. The Begg-Mazumdar $($ Tau $=-0.28, p=0.137)$ and Egger tests did not indicate publication bias (interception $=-4.35, \mathrm{p}=0.006$ ). The metaregression analyzes did not indicate the existence of moderation of the effects by sex (coefficient $=0.0170,95 \%$ CI -0.0080 to $0.0421, \mathrm{p}=0.1818, \mathrm{R}^{2}=0.00$ ), age (coefficient $=0.0058,95 \% \mathrm{CI}$ 0.0184 to $0.0300, \mathrm{p}=0.6395, \mathrm{R}^{2}=0.00$ ), limit of detection of the assay used (coefficient $=0.0020,95 \%$ CI -0.0575 to $0.0615, \mathrm{p}=$ $\left.0.9476, \mathrm{R}^{2}=0.00\right)$, and time after infection that IFN-I was measured (coefficient $=0.0400,95 \%$ CI -0.1057 to $0.1857, \mathrm{p}=$ $\left.0.5906, \mathrm{R}^{2}=0.00\right)$. Between mild and critical, with data grouped from four studies, the difference was also not significant (SMD = $0.203,95 \%$ CI -0.363 to $0.770, \mathrm{p}=0.481, \mathrm{I} 2=64.06$ ) (Figure 3 ). The pooled data from nine studies showed a significant difference between healthy individuals and patients with mild disease $(\mathrm{SMD}=0.447,95 \% \mathrm{CI} 0.085$ to $0.810, \mathrm{p}=0.016, \mathrm{I} 2=$ 62.89) (Figure 4). Between healthy individuals and patients with severe disease the difference was not significant $(\mathrm{SMD}=-0.466$, 95\% CI -0.939 to $0.008, \mathrm{p}=0.054, \mathrm{I} 2=74.73$ ) (Figure 5).

\section{DISCUSSION}

Our results indicate that the circulating levels of IFN- $\alpha$ alone are not determinant in the clinical status of patients affected by COVID-19. We found a significant difference in the plasma protein levels of IFN- $\alpha$ between healthy individuals and mild to moderate cases of COVID-19, which is expected since IFN- $\alpha$ increases during viral infection. Most of the studies included in our meta-analysis, which analyzed healthy controls and COVID-19 patients, found 
TABLE 1 | Main characteristics of the selected articles.

\begin{tabular}{|c|c|c|c|c|c|c|c|c|}
\hline Authors & $\mathbf{N}(\%$ men) & $\begin{array}{c}\text { Mean } \\
\text { Age }\end{array}$ & Kit Source & Methodology & $\begin{array}{l}\text { IFN-I } \\
\text { Subtype }\end{array}$ & $\begin{array}{l}\text { Time } \\
\text { (days) }\end{array}$ & $\begin{array}{l}\text { Limit of detection } \\
\qquad(\mathrm{pg} / \mathrm{ml})\end{array}$ & $\begin{array}{l}\text { Number of participants } \\
\text { that IFN was measured } \\
\text { (detected) }\end{array}$ \\
\hline Arunachalam et al. & $76(58 \%)$ & 55 & Simoa Technology & Single molecular array & $\mathrm{IFN}-\alpha$ & $0-40$ & 0.003 & $58(57)$ \\
\hline Chi et al. & $70(56 \%)$ & 43.4 & $\begin{array}{l}\text { Bio-Plex Pro Human Cytokine Screening 48-plex } \\
\text { panel (BioRad) }\end{array}$ & Luminex magnetic bead & IFN- $\alpha 2$ & 11 & 0.49 & $34(34)$ \\
\hline Galani et al. & 32 (69\%) & 63 & High sensitivity ELISA (Abcam) & ELISA & IFN- $\alpha$ & 01-03 & 1.0 & $26(26)$ \\
\hline Hadjadj et al. & $50(58 \%)$ & 55 & Simoa Technology (Quanterix) & Single molecular array & IFN- $\alpha 2$ & 10 & 0.003 & $50(50)$ \\
\hline Henry et al. & $52(57.7 \%)$ & 51 & U-Plex assay (MSD) & Electro chemiluminescence & IFN- $\alpha 2 a$ & 7 & 4.0 & $52(52)$ \\
\hline Kwon et al. & $31(42 \%)$ & 50 & Cytometric bead array (BD Bioscience) & $\begin{array}{l}\text { Bead-based immunoassay for } \\
\text { Flow cytometry }\end{array}$ & IFN- $\alpha$ & $05-10$ & 1.5 & $31(8)$ \\
\hline Liu et al. & $12(66.7 \%)$ & 62.5 & $\begin{array}{l}\text { BioPlex Pro Human Cytokine Screening Panel } \\
\text { (BioRad) }\end{array}$ & Luminex magnetic bead & IFN- $\alpha 2$ & $07-10$ & 0.49 & $20(20)$ \\
\hline Lucas et al. & $113(46 \%)$ & 62.9 & $\begin{array}{l}\text { Human Cytokine Array/ Chemokine Array 71-403 } \\
\text { Plex Panel (HD71) }\end{array}$ & Luminex magnetic bead & IFN- $\alpha 2$ & 10 & 6.56 & $221(u)$ \\
\hline Ruetsch et al. & $151(66 \%)$ & 51 & Ella custom-design cartrigge (Protein Simple) & $\begin{array}{l}\text { Microfluid immunoassay } \\
\text { fluorescence detection }\end{array}$ & $\mathrm{IFN}-\alpha$ & - & 0.39 & $110(0)$ \\
\hline $\begin{array}{l}\text { Sánchez-Cerrillo et } \\
\text { al. }\end{array}$ & $64(57.8 \%)$ & 61 & $\begin{array}{l}\text { Human IFN- } \alpha \text { all subtypes Serum ELISA kit (pbl } \\
\text { assay science) }\end{array}$ & ELISA & IFN- $\alpha$ & 8 & 1.95 & $64(10)$ \\
\hline Silvin et al. & $158(44 \%)$ & 53 & $\begin{array}{l}\text { Ultra-sensitive assay S-plex Human IFN- } \alpha 2 a \text { kit } \\
\text { (MSD) }\end{array}$ & Electro chemiluminescence & IFN- $\alpha 2 a$ & - & 0.0049 & $83(83)$ \\
\hline Tincati et al. & $40(83 \%)$ & 61 & Cytometric bead array (BD Bioscience) & $\begin{array}{l}\text { Bead-based immunoassay for } \\
\text { Flow cytometry }\end{array}$ & IFN- $\alpha$ & 7 & 1.5 & $40(u)$ \\
\hline Turnbull et al. & 63 (49.3\%) & 55.6 & $\begin{array}{l}\text { Cytokine Human Magnetic } 35 \text { Plex Panel, } \\
\text { (ThermoFisherScientific) }\end{array}$ & Luminex magnetic bead & $\mathrm{IFN}-\alpha$ & 9 & 30 & $54(u)$ \\
\hline Thwaites et al. & $471(64.9 \%)$ & 58.4 & Simoa Technology (Quanterix) & Single molecular array & $\mathrm{IFN}-\alpha$ & 9 & 0.003 & $52(52)$ \\
\hline Yang et al. & $93(60 \%)$ & 46.4 & $\begin{array}{l}\text { Human Th1/2 cytokine kit II (ACEA NovoCyte, } \\
\text { Guangzhou, China) }\end{array}$ & $\begin{array}{l}\text { Bead-based immunoassay for } \\
\text { Flow cytometry }\end{array}$ & IFN- $\alpha$ & - & - & $93(93)$ \\
\hline
\end{tabular}

u, unavailable. 
TABLE 2 | Quality assessment of studies using the Newcastle-Ottawa scale.

\begin{tabular}{lcccc}
\hline Studies & Selection & Comparability & Exposure & Total \\
\hline Arunachalan et al. & 3 & 2 & 2 & 7 \\
Chi et al. & 4 & 2 & 2 & 8 \\
Galani et al. & 4 & 2 & 2 & 8 \\
Hadjadj et al. & 4 & 2 & 2 & 8 \\
Henry et al. & 4 & 2 & 1 & 7 \\
Kwon et al. & 4 & 2 & 2 & 8 \\
Liu et al. & 4 & 2 & 2 & 8 \\
Lucas et al. & 4 & 2 & 2 & 8 \\
Ruetsch et al. & 3 & 2 & 2 & 7 \\
Sánchez-Cerrillo et al. & 4 & 2 & 2 & 8 \\
Silvin et al. & 4 & 2 & 2 & 8 \\
Tincati et al. & 4 & 2 & 2 & 8 \\
Turnbull et al. & 4 & 2 & 2 & 8 \\
Thwaites et al. & 3 & 2 & 2 & 7 \\
Yang et al. & 4 & & 1 & 7 \\
\hline
\end{tabular}

differences in the IFN- $\alpha$ levels. However, we compared the data from severe patients, and no significant differences were found between the groups. To our knowledge, this is the first systematic review and meta-analysis associating the circulating levels of IFN-I with the COVID-19 severity.

Regarding the susceptibility to severe COVID-19, Beck et al. (61), in a qualitative review of the literature, provide the perspective that impaired type I interferon response might be a hallmark of severe COVID-19. Still, our findings provide insight that this is not the case, at least for IFN- $\alpha$ circulating levels. However, they also described studies that did not fit our inclusion criteria, such as the study of Zhang et al. (82), that reported in a large genetic sequencing effort to define risk factors to SARS-CoV-2 infection an association with defects in genes of TLR3 and IRF7 - dependent induction and amplification of IFNI. Also, these authors highlighted the study of Bastard et al. (31), who found the presence of autoantibodies against interferons, including IFN- $\alpha$, in at least $10 \%$ of patients with life-threatening COVID-19. These autoantibodies lead to a plasma reduction of IFN-I, facilitating the viral cycle since the host's response against it is weakened and increasing the chances of the patient manifesting the severe or critical form of the disease (31). In line with this hypothesis, another article that could not be included in our meta-analysis due to its study design, carried out by Trouillet-Assant et al. (32), assumed that patients who have a decreased plasma concentration of this cytokine have a poor prognosis, whereas patients with the lowest IFN-I concentration have longer stay in the ICU, strengthening the crucial role of IFN-I in antiviral responses.

Another point is that we did not meta-analyze studies measuring IFN- $\beta$ levels because only a few studies performed these analyses. IFN-I concentrations are tightly regulated and normally difficult to be measured. Hadjadj et al. demonstrated that patients affected by COVID-19 present undetectable IFN- $\beta$ gene expression and circulating protein in plasma (70). Additionally, an impaired IFN-I response can occur due to the evasion mechanisms of SARS-CoV-2, which allows the virus module to host the immune response. Among these mechanisms is the inhibition of IFN-I production through non-structural protein, such as nsp6, the inhibition of IFN-I signaling through nsp1 (83), and the possible antagonism by nsp13 and the accessory protein ORF6 (84), and more recently, the role of M protein in inhibiting RIG/MDA signaling (85).

Further studies addressed the role of IFN-I during SARSCoV-2 infection, analyzing IFN-I and ISGs gene expression using molecular approaches, particularly single-cell RNA sequencing analysis, which was also not included in our metaanalysis (86-88). Studies carried out with single-cell RNA sequencing determined a hyperactivation of the IFN-I signaling pathways in critically ill patients, contributing to immune dysfunction, leading to exaggerated reactions that can

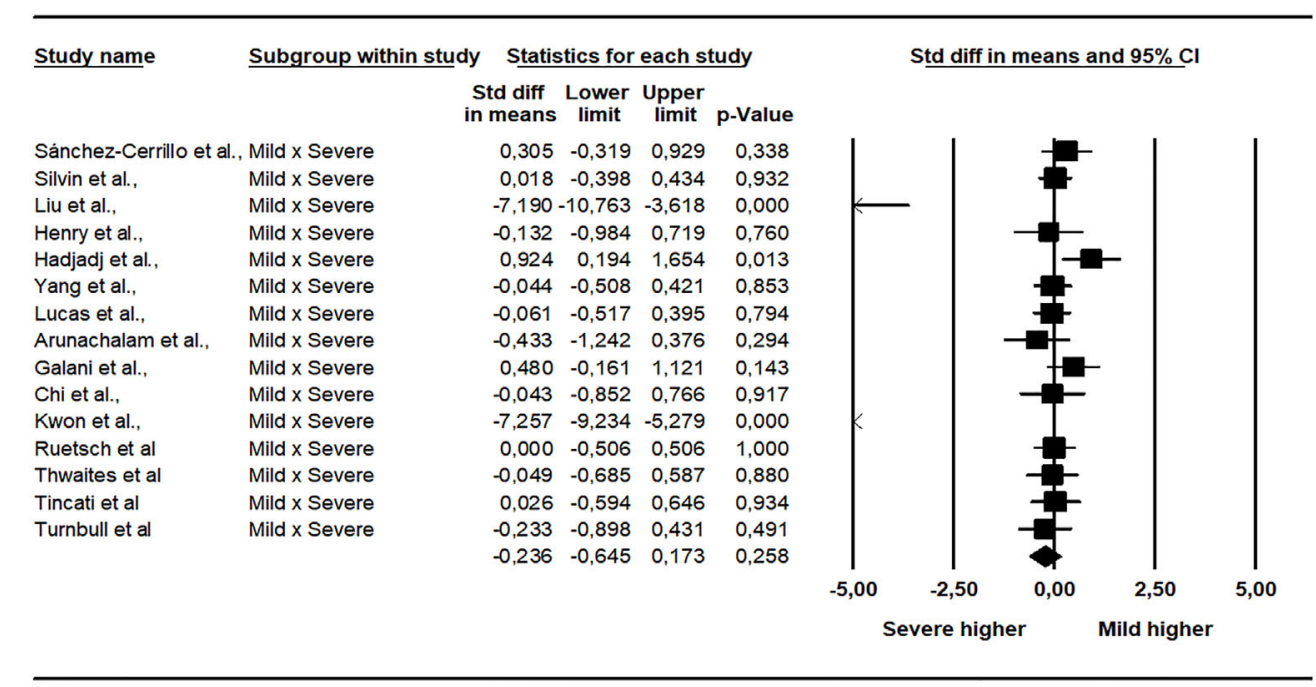

Meta Analysis

FIGURE 2 | Comparison of plasma IFN- $\alpha$ concentration between mild and severe patients. 


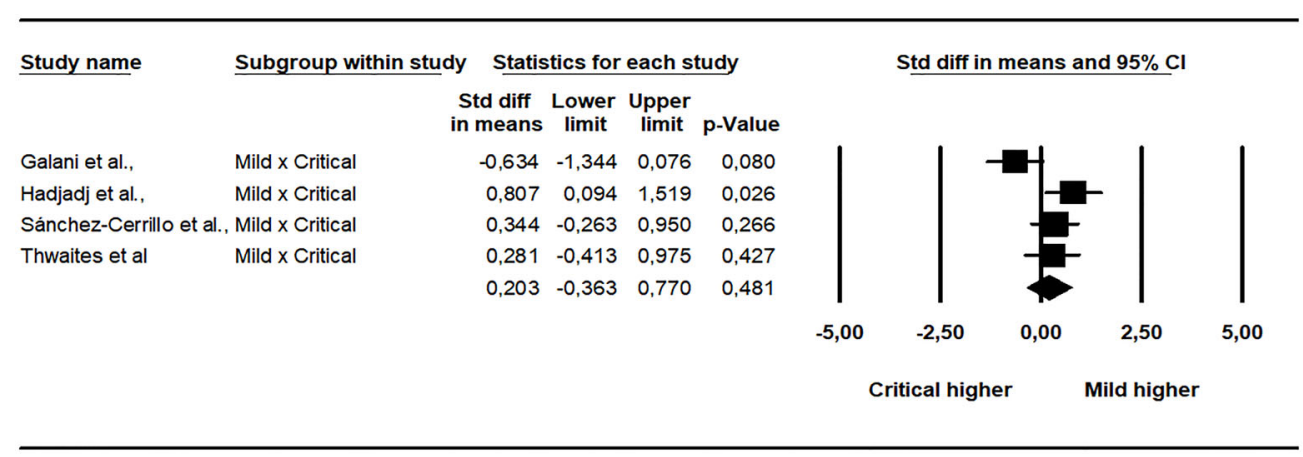

Meta Analysis

FIGURE 3 | Comparison of plasma IFN- $\alpha$ concentration between mild and critical patients.

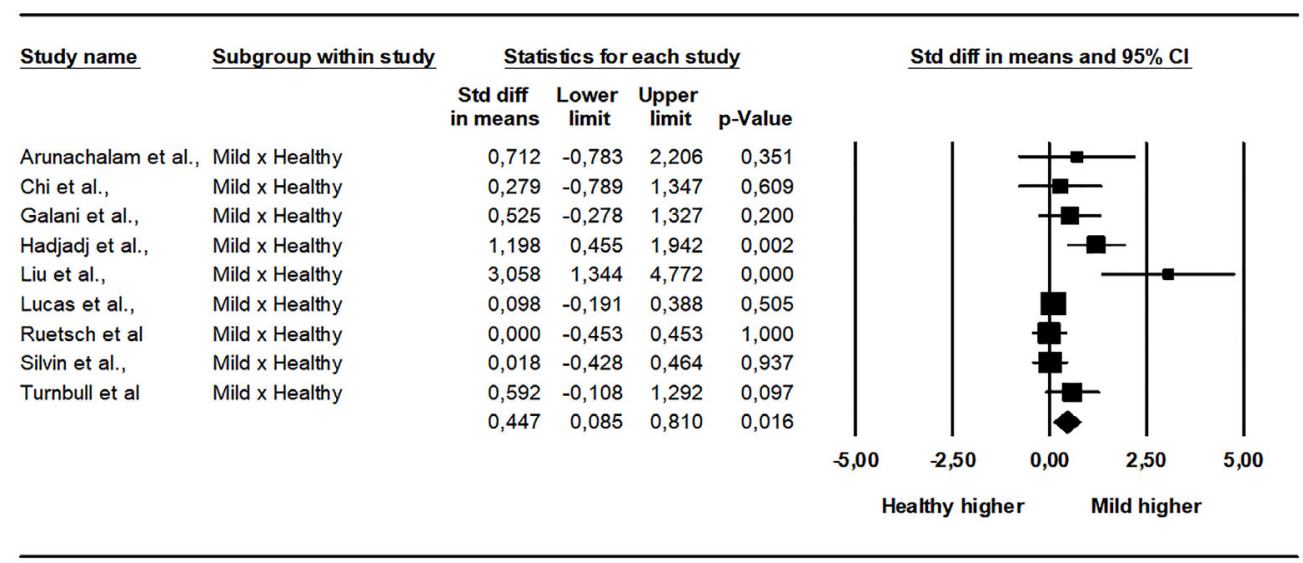

Meta Analysis

FIGURE 4 | Comparison of plasma IFN- $\alpha$ concentration between mild patients and healthy individuals.

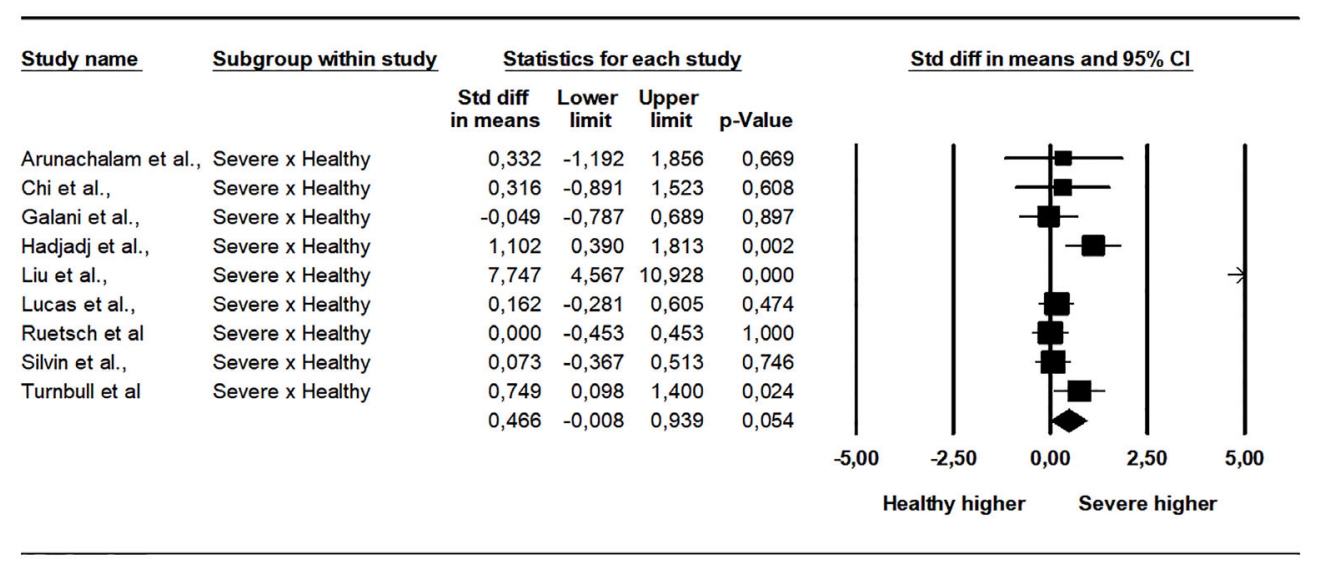

Meta Analysis

FIGURE 5 | Comparison of plasma IFN- $\alpha$ concentration between severe patients and healthy individuals and. 
damage tissues and impair the patient's evolution $(88,89)$ mainly at the pulmonary level. This was observed in post-mortem analyzes performed on patients who die due to COVID-19, as they had a high concentration of IFN-I in lung tissues (90). Also, Menezes et al. investigated the interferon, I, II, and III gene expression at the nasal mucosa of COVID-infected patients. These authors found that higher levels of the IFNB1 transcript predicted poor outcomes (91). However, children with COVID19 present higher levels of IFN- $\alpha$ in nasal fluid than adults and present less severe symptoms, indicating a good outcome (92).

The immunopathogenic role of IFN-I also occurs when an infection has a prolonged duration (93). IFN-I's role in exacerbating pulmonary inflammation is due to the recruitment of NK cells, T cells, dendritic cells, monocytes, and macrophages through the release of chemokines, such as CCL2 and CXCL10 (60). IFN-I also potentiates the inflammatory response induced by TNF- $\alpha$ and IL- $1 \beta$ in severe disease progression (90), and IFN- $\alpha$ may be the main cytokine mediating these responses (94). A late release of IFN-I in response to SARS-CoV-2, in addition to a superabundant response of the innate immune system, capable of a proinflammatory reaction with immunopathogenic potential, might be the reason for a poor outcome $(73,95)$. The IFN- $\alpha$ role in the COVID-19 might depend on the instant when the initial response was launched, the possible interferences in that response, such as the mechanisms of viral evasion and genetic host mutations, and the duration of the infection.

\section{Limitations}

The present study has some limitations. First, only a small number of articles are included since the subject is recent and does not have many studies exploring the theme in depth. Second, high heterogeneity was found among the studies analyzed and due to the small number of studies. Another limitation is the low sensitivity of the assays used in some studies to measure IFN- $\alpha$, which might be why IFN- $\alpha$ has not been detected in many cases. An ultrasensitive method is recommended to measure the circulating levels of IFN-I. Although the progression of the infection might affect the levels of IFN- $\alpha$, in our study, this parameter did not have a significant influence, as demonstrated by the meta-regression analysis.

\section{REFERENCES}

1. World Health Organization. Who Coronavirus Disease (Covid-19) Dashboard (2020). Available at: https://covid19.who.int/ (Accessed April 09, 2021).

2. García LF. Immune Response, Inflammation, and the Clinical Spectrum of COVID-19. Front Immunol (2020) 11:144. doi: 10.3389/fimmu.2020.0144

3. Li Q, Guan X, Wu P, Wang X, Zhou L, Tong Y, et al. Early Transmission Dynamics in Wuhan, China, of Novel Coronavirus-Infected Pneumonia. N Engl J Med (2020) 382:13. doi: 10.1056/NEJMoa2001316

4. Xu XW, Jiang XG, Xu KJ, Ying LJ, Ma CL, Li SB, et al. Clinical Findings in a Group of Patients Infected With the 2019 Novel Coronavirus (SARS-Cov-2) Outside of Wuhan, China: Retrospective Case Series. BMJ (2020) 368:606. doi: 10.1136/bmj.m606

5. Zhang JJ, Dong X, Cao YY, Yuan YD, Yan YB, Yan YQ, et al. Clinical Characteristics of 140 Patients Infected With SARS-CoV-2 in Wuhan, China. Allergy: Eur J Allergy Clin Immunol (2020) 75:7. doi: 10.1111/all.14238

\section{CONCLUSION}

With the current systematic review and meta-analysis, it is possible to conclude that the plasma protein levels of type I IFN, based on peripheral measurement of IFN- $\alpha$, do not demonstrate significant differences between mild, severe, or critical patients. Therefore, IFN- $\alpha$ cannot be used alone as a severity marker for COVID-19.

\section{DATA AVAILABILITY STATEMENT}

The raw data supporting the conclusions of this article will be made available by the authors, without undue reservation.

\section{AUTHOR CONTRIBUTIONS}

RS performed the database search, extracted the data and wrote the manuscript. JB performed the database search as a second reviewer. FS carried out the meta-analysis and revised the manuscript. AS idealized the hypothesis, revised the database search and the manuscript. RZ performed the final review of the manuscript. All authors contributed to the article and approved the submitted version.

\section{FUNDING}

FAPERGS - Edital emergencial COVID-19 processo 20/25510000258-6. Capes - Financial Code 1 and CNPq.

\section{SUPPLEMENTARY MATERIAL}

The Supplementary Material for this article can be found online at: https://www.frontiersin.org/articles/10.3389/fimmu.2021. 657363/full\#supplementary-material

6. Kabeerdoss J, Danda D. Understanding Immunopathological Fallout of Human Coronavirus Infections Including COVID-19: Will They Cross the Path of Rheumatologists? Int J Rheum Dis (2020) 23:8. doi: 10.1111/1756185X.13909

7. Huang C, Wang Y, Li W, Ren L, Zhao J, Hu W, et al. Clinical Features of Patients Infected With 2019 Novel Coronavirus in Wuhan, China. Lancet (2020) 395:497-506. doi: 10.1016/S0140-6736(20)30183-5

8. Ejaz H, Alsrhani A, Zafar A, Javed H, Junaid K, Aabdalla AE, et al. Covid-19 and Comorbidities: Deleterious Impact on Infected Patients. J Infect Public Health (2020) 13:1876-0341. doi: 10.1016/j.jiph.2020.07.014

9. Xavier AR, Silva JS, Almeida JP, Conceição JP, Lacerda S, Kanaan S. Covid-19: Manifestações Clínicas E Laboratoriais Na Infecção Pelo Novo Coronavírus. J Bras Patol Med Lab (2020) 56:1-9. doi: 10.5935/1676-2444.20200049

10. Elshazli RM, Toraih EA, Elgaml A, EL-Mowafy M, EL-Mesery M, Amin M, et al. Diagnostic and Prognostic Value of Hematological and Immunological Markers in COVID-19 Infection: A Meta-Analysis of 6320 Patients. PLoS One (2020) 15(8):e0238160. doi: 10.1371/journal.pone.0238160 
11. Violetis OA, Chasouraki AM, Giannou AM, Baraboutis IG. Covid-19 Infection and Haematological Involvement: A Review of Epidemiology, Pathophysiology and Prognosis of Full Blood Count Findings [Published Online Ahead of Print, 2020 Jun 29]. SN Compr Clin Med (2020) 2:1-5. doi: 10.1007/s42399-020-00380-3

12. Jenkins M, Mccaw TR, Goepfert PA. Mechanistic Inferences From Clinical Reports of SARS-Cov-2. Infect Dis (2020) 52:8. doi: 10.1080/ 23744235.2020.1769853

13. Leisman DE, Ronner L, Pinotti R, Taylor MD, Sinha P, Calfee C, et al. Cytokine Elevation in Severe and Critical COVID-19: A Rapid Systematic Review, MetaAnalysis, and Comparison With Other Inflammatory Syndromes. Lancet Respir Med (2020) 8(12):1233-44. doi: 10.1016/S2213-2600(20)30404-5

14. Brodin P. Immune Determinants of COVID-19 Disease Presentation and Severity. Nat Med (2021) 27:28-33. doi: 10.1038/s41591-020-01202-8

15. Huang Y, Dai H, Ke R. Principles of Effective and Robust Innate Immune Response to Viral Infections: A Multiplex Network Analysis. Front Immunol (2019) 10:173. doi: 10.3389/fimmu.2019.0173

16. Hoffmann HH, Schneider WM, Rice CM. Interferons and Viruses: An Evolutionary Arms Race of Molecular Interactions. Trends Immunol (2015) 36(3):124-38. doi: 10.1016/j.it.2015.01.004

17. Mcnab F, Mayer-Barber K, Sher A, Wack A, O'garra A. Type I Interferons in Infectious Disease. Nat Rev Immunol (2015) 15:87-103. doi: 10.1038/nri3787

18. Paul F, Pellegrini S, Uzé G. Ifna2: The Prototypic Human Alpha Interferon. Gene (2015) 567(2):132-7. doi: 10.1016/j.gene.2015.04.087

19. Steinke JW, Rosenwasser LJ, Borish L. Cytokines in Allergic Inflammation. In: NF Adkinson, editor. Middleton's Allergy: Principles and Practice, vol. 5. United States of America: Elsevier (2014). p. 65-82.

20. Crouse J, Kalinke U, Oxenius A. Regulation of Antiviral T Cell Responses by Type I Interferons. Nat Rev Immunol (2015) 15:4. doi: 10.1038/nri3806

21. Cella M, Jarrossay D, Facchetti F, Alebardi O, Nakajima H, Lanzavecchia A, et al. Plasmacytoid Monocytes Migrate to Inflamed Lymph Nodes and Produce Large Amounts of Type I Interferon. Nat Med (1999) 5:919-23. doi: $10.1038 / 11360$

22. Kawai T, Akira S. Toll-Like Receptors and Their Crosstalk With Other Innate Receptors in Infection and Immunity. Immunity (2011) 34(5):637-50. doi: 10.1016/j.immuni.2011.05.006

23. Reizis B, Bunin A, Ghosh HS, Lewis KL, Sisirak V. Plasmacytoid Dendritic Cells: Recent Progress and Open Questions. Annu Rev Immunol (2011) 29:163-83. doi: 10.1146/annurev-immunol-031210-101345

24. Schoggins JW. Interferon-Stimulated Genes: Roles in Viral Pathogenesis. Curr Opin Virol (2014) 6:40-6. doi: 10.1016/j.coviro.2014.03.006

25. Klotz D, Gerhauser I. Interferon-Stimulated Genes-Mediators of the Innate Immune Response During Canine Distemper Virus Infection. Int J Mol Sci (2019) 20:7. doi: 10.3390/ijms20071620

26. Robertsen B. The Role of Type I Interferons in Innate and Adaptive Immunity Against Viruses in Atlantic Salmon. Dev Comp Immunol (2008) 80:41-52. doi: $10.1016 /$ j.dci.2017.02.005

27. Schoggins JW. Interferon-Stimulated Genes: What Do They All do? Annu Rev Virol (2019) 6:567-84. doi: 10.1146/annurev-virology-092818-015756

28. Reyes L, Sanchez-Garcia MA, Morrison T, Howden AJM, Watts ER, Arienti S, et al. A Type I IFN, Prothrombotic Hyperinflammatory Neutrophil Signature is Distinct for COVID-19 Ards. Wellcome Open Res (2021) 6:38. doi: 10.12688/wellcomeopenres.16584.1

29. Birra D, Benucci M, Landolfi L, Merchionda A, Loi G, Amato P, et al. COVID 19: A Clue From Innate Immunity. Immunol Res (2020) 68:3. doi: 10.1007/ s12026-020-09137-5

30. Lee JS, Shin EC. The Type I Interferon Response in COVID-19: Implications for Treatment. Nat Rev Immunol (2020) 20:10. doi: 10.1038/s41577-020-00429-3

31. Bastard P, Rosen LB, Zhang Q, Michailidis E, Hoffmann HH, Zhang YU, et al. Autoantibodies Against Type I Ifns in Patients With Life-Threatening COVID-19. Science (2020) 370:6515. doi: 10.1126/science.abd4585

32. Trouillet-Assant S, Viel S, Gaymard A, Pons S, Richard JC, Perret M, et al. Type I IFN Immunoprofiling in COVID-19 Patients. J Allergy Clin Immunol (2020) 146(1):206-8. doi: 10.1016/j.jaci.2020.04.029

33. Lee JS, Park S, Jeong HW, Ahn J, Choi SJ, Lee H, et al. Immunophenotyping of covid-19 and Influenza Highlights the Role of Type I Interferons in Development of Severe covid-19. Sci Immunol (2020) 5:49. doi: 10.1126/ sciimmunol.abd1554
34. Galani IE, Triantafyllia V, Eleminiadou EE, Koltsida O, Stavropoulos A, Manioudaki $\mathrm{M}$, et al. Interferon- $\lambda$ Mediates non-Redundant Front-Line Antiviral Protection Against Influenza Virus Infection Without Compromising Host Fitness. Immunity (2017) 46:5. doi: 10.1016/ j.immuni.2017.04.025

35. Agrawal A. Mechanisms and Implications of Age-Associated Impaired Innate Interferon Secretion by Dendritic Cells: A Mini-Review. Gerontology (2013) 59(5):421-6. doi: 10.1159/000350536

36. Stout-Delgado HW, Yang X, Walker WE, Tesar BM, Goldstein DR. Aging Impairs IFN Regulatory Factor 7 Up-Regulation in Plasmacytoid Dendritic Cells During TLR9 Activation. J Immunol (2008) 181(10):6747-56. doi: 10.4049/jimmunol.181.10.6747

37. Molony RD, Nguyen JT, Kong Y, Montgomery RR, Shaw AC, Iwasaki A. Aging Impairs Both Primary and Secondary RIG-I Signaling for Interferon Induction in Human Monocytes. Sci Signal (2017) 10(509):eaan2392. doi: 10.1126/scisignal.aan2392

38. Webb K, Peckham H, Radziszewska A, Menon M, Oliveri P, Simpson S, et al. Sex and Pubertal Differences in the Type 1 Interferon Pathway Associate With Both X Chromosome Number and Serum Sex Hormone Concentration. Front Immunol (2019) 9:3167. doi: 10.3389/fimmu.2018.03167

39. Perrotta F, Corbi G, Mazzeo G, Boccia M, Aronne L, D'agnano V, et al. COVID-19 and the Elderly: Insights Into Pathogenesis and Clinical DecisionMaking. Aging Clin Exp Res (2020) 32:1599-608. doi: 10.1007/s40520-02001631-y

40. Zhou F, Yu T, Du R, Fan G, Liu Y, Liu Z, et al. Clinical Course and Risk Factors for Mortality of Adult Inpatients With COVID-19 in Wuhan, China: A Retrospective Cohort Study. Lancet (2020) 395(10229):1054-62. doi: 10.1016/S0140-6736(20)30566-3

41. Peckham H, de Gruijter NM, Raine C, Radziszewska A, Ciurtin C, Wedderburn LR, et al. Male Sex Identified by Global COVID-19 MetaAnalysis as a Risk Factor for Death and ITU Admission. Nat Commun (2020) 11:6317. doi: 10.1038/s41467-020-19741-6

42. Cole SW, Shanahand MJ, Gaydoshf L, Harris KM. Population-Based RNA Profiling in Add Health Finds Social Disparities in Inflammatory and Antiviral Gene Regulation to Emerge by Young Adulthood. PNAS (2019) 117:9. doi: $10.1073 /$ pnas. 1821367117

43. Ziegler CGK, Allon SJ, Nyquist SK, Mbano IM, Miao VN, Tzouanas CN, et al. Sars-CoV-2 Receptor ACE2 is an Interferon-Stimulated Gene in Human Airway Epithelial Cells and is Detected in Specific Cell Subsets Across Tissues. Cell (2020) 181:5. doi: 10.1016/j.cell.2020.04.035

44. Onabajo OO, Banday AR, Stanifer ML, Yan W, Obajemu A, Santer DM, et al. Interferons and Viruses Induce a Novel Truncated ACE2 Isoform and Not the Full-Length SARS-CoV-2 Receptor. Nat Genet (2020) 52:1283-93. doi: 10.1038/s41588-020-00731-9

45. Rong L, Perelson AS. Treatment of Hepatitis C Virus Infection With Interferon and Small Molecule Direct Antivirals: Viral Kinetics and Modeling. Crit Rev Immunol (2010) 30:2. doi: 10.1615/critrevimmunol. v30.i2.30

46. LI G, De Clercq E. Current Therapy for Chronic Hepatitis C: The Role of Direct-Acting Antivirals. Antiviral Res (2017) 142:83-122. doi: 10.1016/ j.antiviral.2017.02.014

47. Broquetas T, Garcia-Retortillo M, Micó M, Canillas L, Puigvehí M, Cañete N, et al. Hepatitis B Surface Antigen and Hepatitis B Core-Related Antigen Kinetics After Adding Pegylated-Interferon to Nucleos(T)Ids Analogues in Hepatitis B E Antigen-Negative Patients. World J Hepatol (2020) 12 (11):1076-88. doi: 10.4254/wjh.v12.111.1076

48. Friedman RM, Contente S. Interferons as Therapy for Viral and Neoplastic Diseases: From Panacea to Pariah to Paragon. Pharmaceuticals (Basel) (2009) 2:3. doi: $10.3390 / \mathrm{ph} 2030206$

49. Wagner SM, Melchardt T, Greil R. Ropeginterferon alfa-2b for the Treatment of Patients With Polycythemia Vera. Drugs Today (Barc) (2020) 56:3. doi: 10.1358/dot.2020.56.3.3107706

50. Zhou Q, Chen V, Shannon CP, Wei XS, Xian X, Wang X, et al. Interferon- $\alpha 2 b$ Treatment for COVID-19. Front Immunol (2020) 11:1061. doi: 10.3389/ fimmu.2020.01061

51. Pereda R, González D, Rivero HB, Rivero JC, Pérez A, López LDR, et al. Therapeutic Effectiveness of Interferon- $\alpha 2 b$ Against COVID-19: The Cuban Experience. J Interferon Cytokine Res (2020) 40:9. doi: 10.1089/jir.2020.0124 
52. Rahmani H, Davoudi-Monfare E, Nourian A, Khalili H, Hajizadeh N, Jalalabadi NZ, et al. Interferon $\beta-1 \mathrm{~b}$ in Treatment of Severe COVID-19: A Randomized Clinical Trial. Int Immunopharmacol (2020) 88:106903. doi: 10.1016/j.intimp.2020.106903

53. WHO Solidarity trial consortium, Pan H, Peto R, Karim QA, Alejandria M, Henao-Restrepo AM, et al. Repurposed Antiviral Drugs for COVID-19 Interim WHO SOLIDARITY Trial Results. NEJM (2020) 384:497-511. doi: 10.1056/NEJMoa2023184

54. Monk PD, Marsden RJ, Tear VJ, Brookes J, Batten TN, Mankowski M, et al. Safety and Efficacy of Inhaled Nebulised Interferon beta-1a (SNG001) for Treatment of SARS-CoV-2 Infection: A Randomised, Double-Blind, PlaceboControlled, Phase 2 Trial. Lancet Respir Med (2020) 9:196-206. doi: 10.1016/ S2213-2600(20)30511-7

55. Abdolvahab M, Moradi-Kalbolandi S, Zarei M, Bose D, Majidzadeh-A K, Farahmand L. Potential Role of Interferons in Treating COVID-19 Patients. Int Immunopharmacol (2020) 90:107171. doi: 10.1016/j.intimp.2020.107171

56. Walz L, Cohen AJ, Rebaza AP, Vanchieri J, Slade MD, Cruz CSD, et al. JAKInhibitor and Type I Interferon Ability to Produce Favorable Clinical Outcomes in COVID-19 Patients: A Systematic Review and Meta-Analysis. BMC Infect Dis (2021) 21:47. doi: 10.1186/s12879-020-05730-z

57. King C, Sprent J. Dual Nature of Type I Interferons in SARS-CoV-2 Induced Inflammation. Trends Immunol (2021) 42:4. doi: 10.1016/j.it.2021.02.003

58. Sa Ribero M, Jouvenet N, Dreux M, Nisole S. Interplay Between SARS-CoV-2 and the Type I Interferon Response. PLoS Pathog (2020) . 16:7. doi: 10.1371/ journal.ppat.1008737

59. Lopez L, Sang PC, Tian Y, Sang Y. Dysregulated Interferon Response Underlying Severe Covid-19. Viruses (2020) 12(12):1433. doi: 10.3390/v12121433

60. Schreiber G. The Role of Type I Interferons in the Pathogenesis and Treatment of COVID-19. Front Immunol (2020) 2020):3389/ fimmu.2020.595739. doi: 10.3389/fimmu.2020.595739

61. Beck DB, Aksentijevich I. Susceptibility to Severe COVID-19. Science (2020) 370(6515):404-5. 10.1126/science.abe7591.

62. Graph Grabber (2020). [S. 1.] Quintessa Ltd. Available at: https://www. quintessa.org/software/downloads-and-demos/graph-grabber-2.0.2 (Accessed November 7, 2020).

63. Wells GA, Shea B, O'connell D, Peterson J, Welch V, Losos M, et al. The Newcastle-Ottawa Scale (NOS) for Assessing the Quality of Nonrandomized Studies in Meta-Analyses (2013). Available at: http://www.ohri.ca/programs/ clinical_epidemiology/oxford.asp (Accessed December 27, 2020).

64. Cohen J. Statistical Power Analysis for the Behavioral Sciences. New York: Academic Press (1988). 469 p.

65. Higgins JP, Thompson SG. Quantifying Heterogeneity in a Meta-Analysis. Stat Med (2002) 21:11. doi: 10.1002/sim.1186

66. Egger M, Smith GD, Schneider M, Minder C. Bias in Meta-Analysis Detected by a Simple, Graphical Test. BMJ (1997) 315:629. doi: 10.1136/bmj.315.7109.629

67. Begg CB, Mazumdar M. Operating Characteristics of a Rank Correlation Test for Publication Bias. Int Biom Soc (1994) 50:4. doi: 10.2307/2533446

68. Silvin A, Chapuis N, Dunsmore G, Goubet AG, Dubuisson A, Derosa L, et al. Elevated Calprotectin and Abnormal Myeloid Cell Subsets Discriminate Severe From Mild Covid-19. . Cell (2020) 182:6. doi: 10.1016/j.cell.2020.08.002

69. Yang AP, Li HM, Tao WQ, Yang XJ, Wang M, Yang WJ, et al. Infection With SARS-CoV-2 Causes Abnormal Laboratory Results of Multiple Organs in Patients. Aging (2020) 12:11. doi: 10.18632/aging.103255

70. Hadjadj J, Yatim N, Barnabei L, Corneau A, Boussier J, Smith N, et al. Impaired Type I Interferon Activity and Inflammatory Responses in Severe COVID-19 Patients. Science (2020) 369:6504. doi: 10.1126/science.abc6027

71. Sánchez-Cerrillo I, Landete P, Aldave B, Sánchez-Alonso S, Sánchez-Azofra A, Marcos-Jiménez A, et al. Covid-19 Severity Associates With Pulmonary Redistribution of CD1c+ DC and Inflammatory Transitional and Nonclassical Monocytes. J Clin Invest (2020) 130:6290-300. doi: 10.1172/ jci140335

72. Galani IE, Rovina N, Lampropoulou V, Triantafyllia V, Manioudaki M, Pavlos E, et al. Untuned Antiviral Immunity in COVID-19 Revealed by Temporal Type IIII Interferon Patterns and Flu Comparison. Nat Immunol (2021) 22:32-40. doi: 10.1038/s41590-020-00840-x

73. Arunachalam PS, Wimmers F, Mok CKP, Perera RAPM, Scott M, Hagan T, et al. Systems Biological Assessment of Immunity to Mild Versus Severe COVID-19 Infection in Humans. Science (2020) 369:6508. doi: 10.1126/SCIENCE.ABC6261
74. Liu Y, Zhang C, Huang F, Yang Y, Wang F, Yuan J, et al. Elevated Plasma Levels of Selective Cytokines in COVID-19 Patients Reflect Viral Load and Lung Injury. Natl Sci Rev (2020) 7:6. doi: 10.1093/nsr/nwaa037

75. Henry BM, Benoit S, Vikse J, Berger B, Pulvino C, Hoehn J, et al. The AntiInflammatory Cytokine Response Characterized by Elevated interleukin-10 is a Stronger Predictor of Severe Disease and Poor Outcomes Than the ProInflammatory Cytokine Response in Coronavirus Disease 2019 (COVID-19). Clin Chem Lab Med (2020) 59(3):599-607. doi: 10.1515/cclm-2020-1284

76. Lucas C, Wong P, Klein J, Castro TBR, Silva J, Sundaram M, et al. Longitudinal Analyses Reveal Immunological Misfiring in Severe COVID19. Nature (2020) 584:463-9. doi: 10.1038/s41586-020-2588-y

77. CHI Y, Ge Y, Wu B, Zhang W, Wu T, Wen T, et al. Serum Cytokine and Chemokine Profile in Relation to the Severity of Coronavirus Disease 2019 in China. J Infect Dis (2020) 222:5. doi: 10.1093/infdis/jiaa363

78. Kwon JS, Kim JY, Kim MJ, Park SJ, Kim BN, Bae S, et al. Factors of Severity in Patients With COVID-19: Cytokine/Chemokine Concentrations, Viral Load, and Antibody Responses. Am J Trop Med Hyg (2020) 103(6):2412-8. doi: $10.4269 /$ ajtmh. $20-1110$

79. Thwaites RS, Uruchurtu AS, Siggins MK, Liew F, Russell CD, Moore SC. Inflammatory Profiles Across the Spectrum of Disease Reveal a Distinct Role for GM-CSF in Severe COVID-19. Sci Immunol (2021) 6:57. doi: 10.1126/ sciimmunol.abg 9873

80. Turnbull I, Fuchs A, Remy K, Kelly M, Frazier E, Ghosh S. Dysregulation of the Leukocyte Signaling Landscape During Acute Covid-19. Res Square [Preprint]. doi: 10.21203/rs.3.rs-244150/v1

81. Tincati C, Cannizzo ES, Giacomelli M, Badolato R, Monforte A, Marchetti G. Heightened Circulating Interferon-Inducible Chemokines, and Activated ProCytolytic Th1-Cell Phenotype Features Covid-19 Aggravation in the Second Week of Illness. Front Immunol (2020) 11:1-12. doi: 10.3389/ fimmu.2020.580987

82. Zhang Q, Bastard P, Liu Z, Pen JL, Moncada-Velez M, Chen J, et al. Inborn Errors of Type I IFN Immunity in Patients With Life-Threatening COVID-19. Science (2020) 370(6515). doi: 10.1126/science.abd4570

83. Xia H, Cao Z, Xie X, Zhang X, Chen J, Wang H, et al. Evasion of Type I Interferon by SARS-Cov-2. Cell Rep (2020) 33:1. doi: 10.1016/j.celrep.2020.108234

84. Yuen CK, Lam JY, Won WM, Mak LF, Wan X, CHU H, et al. Sars-CoV-2 nsp13, nsp14, nsp15 and Orf6 Function as Potent Interferon Antagonists. Emerg Microbes Infect (2020) 9:1. doi: 10.1080/22221751.2020.1780953

85. Zheng Y, Zhuang MW, Han L, Zhang J, Nan ML, Zhan P, et al. Severe Acute Respiratory Syndrome Coronavirus 2 (SARS-CoV-2) Membrane (M) Protein Inhibits Type I and III Interferon Production by Targeting RIG-I/MDA-5 Signaling. Signal Transduct Targeted Ther (2020) 5(1). doi: 10.1038/s41392020-00438-7

86. Saichi M, Ladjemi MZ, Korniotis S, Rousseau C, Zakaria AIT-hamou Z, Massenet L, et al. Single Cell RNA Sequencing of Blood Antigen-Presenting Cells in Severe Covid-19 Reveals Multi-Process Defects in Antiviral Immunity. bioRxiv [Preprint] (2020). doi: 10.1101/2020.07.20.212837

87. Yao C, Bora SA, Parimon T, Zaman T, Friedman OA, Palatinus JA, et al. CellType-Specific Immune Dysregulation in Severely Ill COVID-19 Patients. Cell Rep (2021) 34(1):108590. doi: 10.1016/j.celrep.2020.108590

88. Zhang JY, Wang XM, Xing X, Xu Z, Zhang C, SONG JW, et al. Single-Cell Landscape of Immunological Responses in Patients With COVID-19. Nat Immunol (2020) 21:9. doi: 10.1038/s41590-020-0762-x

89. Huang L, Shi Y, Gong B, Jiang L, Liu X, Yang J, et al. Blood Single Cell Immune Profiling Reveals the interferon-MAPK Pathway Mediated Adaptive Immune Response for COVID-19. medRxiv [Preprint] (2020). doi: 10.1101/ 2020.03.15.20033472

90. Lee JS, Park S, Jeong HW, Ahn J, Choi SJ, Lee H, et al. Immunophenotyping of covid-19 and Influenza Highlights the Role of Type I Interferons in Development of Severe Covid-19. Sci Immunol (2020) 5:49. doi: 10.1126/ sciimmunol.abd1554

91. Menezes SM, Braz M, Llorens-Rico V, Wauters J, Van Weyenbergh J. Endogenous Ifn $\beta$ Expression Predicts Outcome in Critical Patients With COVID-19. Lancet Microbe (2021). doi: 10.1016/S2666-5247(21)00063-X. Epub ahead of print.

92. Pierce CA, Sy S, Galen B, Goldstein DY, Orner EP, Keller MJ, et al. Natural Mucosal Barriers and COVID-19 in Children. JCI Insight (2021) 6:148694. doi: $10.1172 /$ jci.insight.148694. Epub ahead of print. 
93. Galani IE, Triantafyllia V, Eleminiadou EE, Koltsida O, Stavropoulos A, Manioudaki $M$, et al. Interferon- $\lambda$ Mediates non-Redundant Front-Line Antiviral Protection Against Influenza Virus Infection Without Compromising Host Fitness. Immunity (2017) 46:5. doi: 10.1016/ j.immuni.2017.04.025

94. Wei L, Ming S, Zou B, Wu Y, Hong Z, Li Z, et al. Viral Invasion and Type I Interferon Response Characterize the Immunophenotypes During Covid-19 Infection. SSRN Electronic J (2020). doi: 10.2139/ssrn.3564998

95. Park A, Iwasaki A. Type I and Type Iii Interferons - Induction, Signaling, Evasion, and Application to Combat Covid-19. Cell Host Microbe (2020) 27:6. doi: 10.1016/j.chom.2020.05.008
Conflict of Interest: The authors declare that the research was conducted in the absence of any commercial or financial relationships that could be construed as a potential conflict of interest.

Copyright (c) 2021 da Silva, Gonçalves, Zanin, Schuch and de Souza. This is an openaccess article distributed under the terms of the Creative Commons Attribution License (CC BY). The use, distribution or reproduction in other forums is permitted, provided the original author(s) and the copyright owner(s) are credited and that the original publication in this journal is cited, in accordance with accepted academic practice. No use, distribution or reproduction is permitted which does not comply with these terms. 